\title{
COLOR SCHEMES OF FACADE SYSTEMS IN NEW DORMITORY DISTRICTS OF SAINT PETERSBURG, RUSSIA
}

\author{
Margarita Asylgaraeva ${ }^{1}$, Nikita Luchinin², Sergey Startsev³ \\ 1,2 Peter the Great Saint Petersburg Polytechnic University \\ Politekhnicheskaya St. 29, St. Petersburg, Russia \\ ${ }^{3}$ BiospaceStroy LLC \\ office 207, Karavannaya St. 1, St. Petersburg, Russia \\ ${ }^{1}$ margarita.asylgaraeva@yandex.ru
}

\begin{abstract}
Fast and extensive transformation of cities is a quite widespread practice nowadays, but it has a disadvantage in affecting the quality of architectural spaces. The main task of architecture, i.e. space arrangement, shall address not only physical needs for comfort, but also visual ones. By means of facade color schemes, it is possible to make a positive impact on the human psychological condition and create a more favorable visual environment. A great number of developers also represents one of the main issues of such large-scale city transformation. At the design stage, the appearance of a new project is not always aligned with the appearance of the existing buildings.

Based on the experience of architects and theoreticians in coloristics and psychology of the spatial environment, modern districts of Saint Petersburg located both in the city and in its vicinity were selected for the analysis conducted in this paper. The study involves identifying the color schemes used as well as a possible impact of such choice on the community. Recommendations on improving the visual architectural space are given.
\end{abstract}

\section{Keywords}

Color environment, coloristics, psychology of the spatial environment.

\section{Introduction}

Nowadays, the rate of urbanization contributes to the intense modification of the city image, affecting the quality of the architectural space. Such city environment, in its turn, has a great impact on the psychological condition of its residents who have to witness every day too bright finish or, on the contrary, monotonous details or not details at all, too simple shapes or incommensurable height of erected buildings.

The architectural environment is a harmoniously created space. The primary task of architecture, i.e. space arrangement, shall address not only physical needs for comfort, but also psychological ones. The facade shall represent the value of a building, serve as a connective between inner and outer space, as well as coordination between old and modern design (Utaberta, 2012).

The organization of building facades in new residential areas is becoming one of the architect's ways to influence the image of the urban environment that people perceive on a daily basis. With the naked eye, it is noticeable that the constructive, volumetric and planning decisions of buildings in new residential areas are not just similar each such building represents only a variation of one typology development - a multistory frame house, very often with a ventilated facade and a large glazing area of balconies and loggias.

Unfortunately, due to the peculiarities of the organization of the construction of buildings of this typology, the change in spatial planning decisions, a significant decrease in the number of storeys, as well as other methods for arranging a comfortable architectural environment do not find the necessary distribution - they are simply unprofitable, their application is connected with the monetary losses of construction organizations. Therefore, one of the real ways to use nowadays to organize a comfortable architectural environment is the 


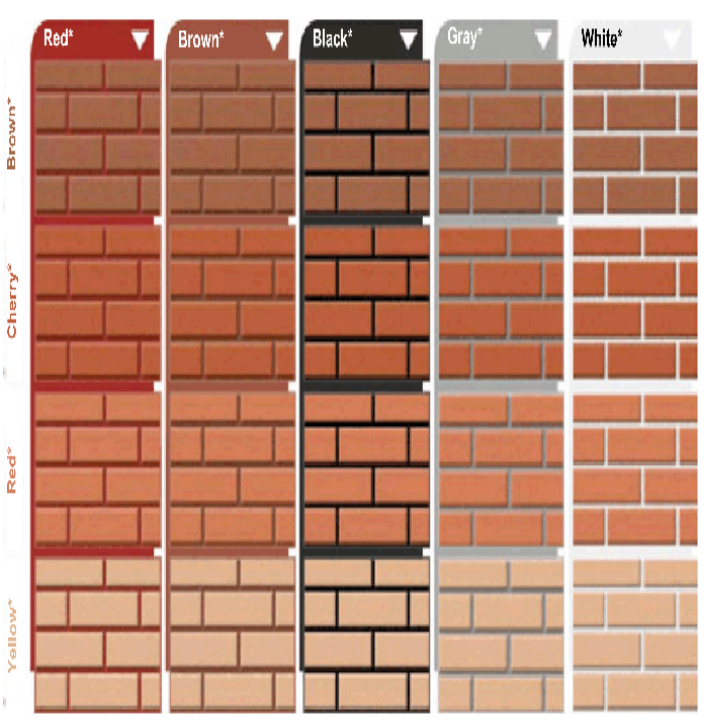

Figure 1. Brickwork color depending on mortar (http://arfaterm.com. ua/article.html?id=28)

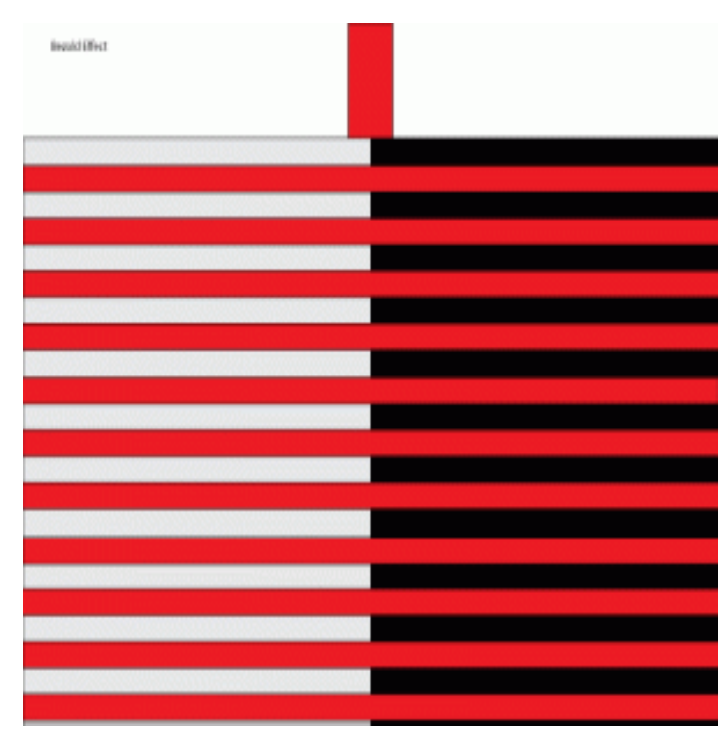

Figure 2. Bezold effect

(https://openlab.citytech.cuny.edu/gchetram-eportfolio/2015/04/27/ color-interactions/)

use of various color schemes for finishing the facades of buildings.

English architect Medd said that color is the only important factor that determines the character of a building (1949). Color can visually change dimensions: e.g. a black square looks smaller on white background than vice versa (Poling, 1975).

Such illusion can be observed when changing traditional colors of window frames in facades, the color of brickwork or panel mortar. It can be accompanied with the assimilation effect (Bezold effect).

Therefore, red bricks will seem lighter combined with white mortar, and darker combined with black mortar (Figures 1, 2).

Scientifically, color is an informative property of shape to reflect light rays of a certain wavelength, through which the eye perceives a variety of feelings (Efimov, 1990). Such feelings can change the general state and psychophysical well-being of a person. Color also performs a variety of other functions: it allows us to get out bearings, emphasizes certain elements, and shapes the urban landscape (Chechelnitsky, 2012).

According to the studies performed by Filin (1990), there are two types of the environment uncomfortable for the human eye: aggressive environment and homogeneous environment. An aggressive field is a field where a great number of similar elements are scattered, e.g. windows in the facade of a multi-story building. With a great number of similar objects in sight, it is difficult for a person to establish what objects he/she was focused on before and what after.

The eye starts to change focus very fast, and the time of its rest decreases. The optimum number of similar elements in sight in the urban environment is 5.13 elements and more result in monotony (Filin, 1990).

In a homogeneous field, there are no visible elements or their number is minimal. In such case, an insufficient amount of information on the object observed is transmitted to the brain, which affects the nervous system and results in a sense of discomfort.

The idea to use color also became common outside Russia in the 1960s during the development of divided Berlin. In parallel with the criticism from pre-war architects who disregarded the use of color to improve mood and reduce monotony formed by large-scale prefabricated housing construction, it was stated that it was possible to "influence people's perceptions and feelings" through color (Pugh, 2014).

Color elicits a response in person, affecting the hormone system, and has either positive or negative effect. There are many typologies classifying colors based on their impact on people, but the generalized classification is based on wavelengths of the visible part of the spectrum.

1. Long wavelength part $-760 \ldots 580 \mathrm{~nm}$. Red, and orange colors belong to this category. They stimulate the brain, energize, and attract attention fast. Red color can symbolize both positive and negative emotions and attitudes, e.g. aggression or warning (see https:// www.thoughtco.com/color-psychology-and-humanbehavior-4151666). Besides, a red object always appears closer that it is (see https://medium.com/studiotmd/ the-perception-of-color-in-architecture-cf360676776c). Orange color is not so strong in terms of the impact as red color; it has a less negative characteristic. However, it can stand out against the background and emphasize low-quality joints of elements, thereby reducing the visual value of a facade.

2. Medium wavelength part $-580 \ldots 510 \mathrm{~nm}$. Yellow contributes to high spirits and sociability, while green, the color, acts soothingly and is considered optimal from the position of favorable influence and when used as a background, creates the effect of increasing the space. Yellow, as a color closest to the sun color, has "a light nature and clarity", but makes "an unpleasant impression" being combined with a cold color or stain (Mesyats, 2012).

Green color is natural and soothing, it represents a balance between yellow and blue. It can be used 
in combination with dark blue, thereby smoothing out its coldness (see https://www.thoughtco.com/colorpsychology-and-human-behavior-4151666; Mesyats, 2012).

3. Short wavelength part $-510 \ldots 380 \mathrm{~nm}$. Blue, purple and light blue belong to this category (Efimov, 1990, Mesyats, 2012). Blue color and its combinations with red in various proportions are sometimes associated with coldness and indifference (see https://www.thoughtco. com/color-psychology-and-human-behavior-4151666, Mesyats, 2012).

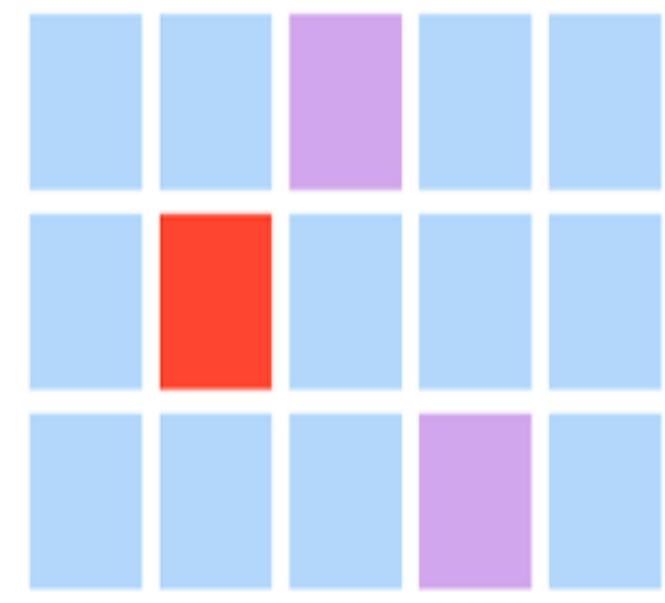

Figure 3. 60-30-10 color rule

( ht tp: //www.e yequant.com/b/og/2013/06/27/ capturing-user-attention-with-color)

However, light-blue and blue also carry peace and in general are one of the most common colors. Purple is a combination of red and blue; light purple symbolizes power and spirituality (Efimov, 1990; see https://www.thoughtco. com/color-psychology-and-human-behavior-4151666). Such colors as brown and gray, black and white are classified separately. Brown represents order and stability, which is why it can be used to set accents, but in combination with gray it has an opposite effect (Poling, 1975; Chechelnitsky, 2012).

Cold gray does not irritate but brings instability and boredom. White color is light and noble. It also helps to set accents and is associated with cleanliness and clarity. Black color helps to concentrate and provides contrast but also brings frustration and dampens the mood (Frieling, 1973; Chechelnitsky, 2012; Rahmatabadi, 2011).

Thus, combining those individual colors with cold and warm hues, it is possible to create color balance having a positive impact on a person. Contrast and the environment shall also be taken into account. The use of cultural elements or patterns with details provides perception of hidden order of buildings, which favorably affects the need to feel safe (Azma, 2017; Feizi, 2013).

There are six types of contrast: dark-light, coldwarm, complementary, simultaneous, qualitative and quantitative. For example, it is possible to obtain two different hues of one color changing the background using simultaneous contrast.

And to compensate for a small volume of light yellow enlarging the space, a bigger area painted with lilac will be necessary (quantitative contrast) (Poling, 1975; Itten, 2013). Yoshizava took the property of simultaneous contrast as the basis for an analysis of "color pollution" in residential complexes of Japan (2007).

According to the results of his experimental research, a light building will better match with the environment of dark hues of the same color, but the existing background has pale hues, then it is necessary to choose a paler hue for a new building. According to the $60-30-10$ color rule (Figure 3 ), balance is created using three colors where dominant color should be used $60 \%$ of the time, secondary color $-30 \%$ of the time, and accent color $-10 \%$ of the time. Typically, dominant color should be less saturated as compared to accent color (see http://www.eyequant. $\mathrm{com} / \mathrm{blog} / 2013 / 06 / 27 /$ capturing-user-attention-withcolor). There is a belief that, due to lack of sufficient light, north areas require self-luminous fluorescent coatings complementing city lighting (Efimov, 1990). On the other hand, where sunlight is scarcer, the colors wanted are softer, duller, and a greater preference for blue is noted. No shiny and strong colors are needed (Birren, 1945). Too bright or neon colors are associated with advertising or signs used to attract short-term attention of pedestrians, and they often do not cause any positive emotions. Initially, such approach became common in the 20th century in an American model of spatial organization in the city, but it was related to the focus on the fast-growing car industry and increase in the speed of moving from $5 \mathrm{~km} / \mathrm{h}$ to 60 km/h (Banham, 1969; Gehl, 2006).

It is not recommended to apply color to vertical elements in vertical lines. Only transversal lines should be used. Individual elements should not be painted in individual colors: it is better to use similar balanced combinations for individual elements. If the shape of an object is complex, the color scheme should be simplified, and vice versa (Asgarzadeh, 2012; Ruskin, 2017).

Based on the experience of architects and theorists in the environment of color design of the architectural space, it is possible to distinguish a number of colors that positively influence the human psyche:

1. Red most effectively attracts attention and causes interest as a prerequisite for activity due to architectural organization (Zabelshansky, 1985). In this case, a large concentration of red color can displace all other colors, causing visual discomfort. It is recommended to use muted tones of red colors in order to take into account the small amount of sunlight in the city.

2. A saturated yellow color without cold shades. However, taking into account possible pollution due to frequent unfavorable weather conditions, it can produce an effect opposite to the "light nature" of the color. It is possible to use in small quantities as an accent color.

3. Blue and green colors and their light shades are well suited for northern regions. Also, the blue color, being a 
color calm, can be used to visually increase the space when used as a background.

4. Brown or black can be used in small amounts for accents, it is not recommended to alternate with gray. White can be used as the main color in a quality performance, it will give lightness and expressiveness.

\section{Subject, tasks and methods of the study}

The objective of this study is to examine options in arranging the color environment of building facades positively or negatively affecting the human psychological condition, as exemplified by new housing construction in Saint Petersburg and the Leningrad Region.
- The subject of the study is color schemes of facade systems of new housing construction.

- Tasks of the study:

1. To develop a method of choosing the color scheme positively affecting the human psychological condition, based on the national and international experience.

2. To identify advantages and disadvantages of the existing residential development in Saint Petersburg, make recommendations.

\section{Methods}

The method of investigation is the analysis of the color schemes of the facades of existing buildings by drawing

Table 1. Impact of the color scheme of facades in new housing construction in Saint Petersburg

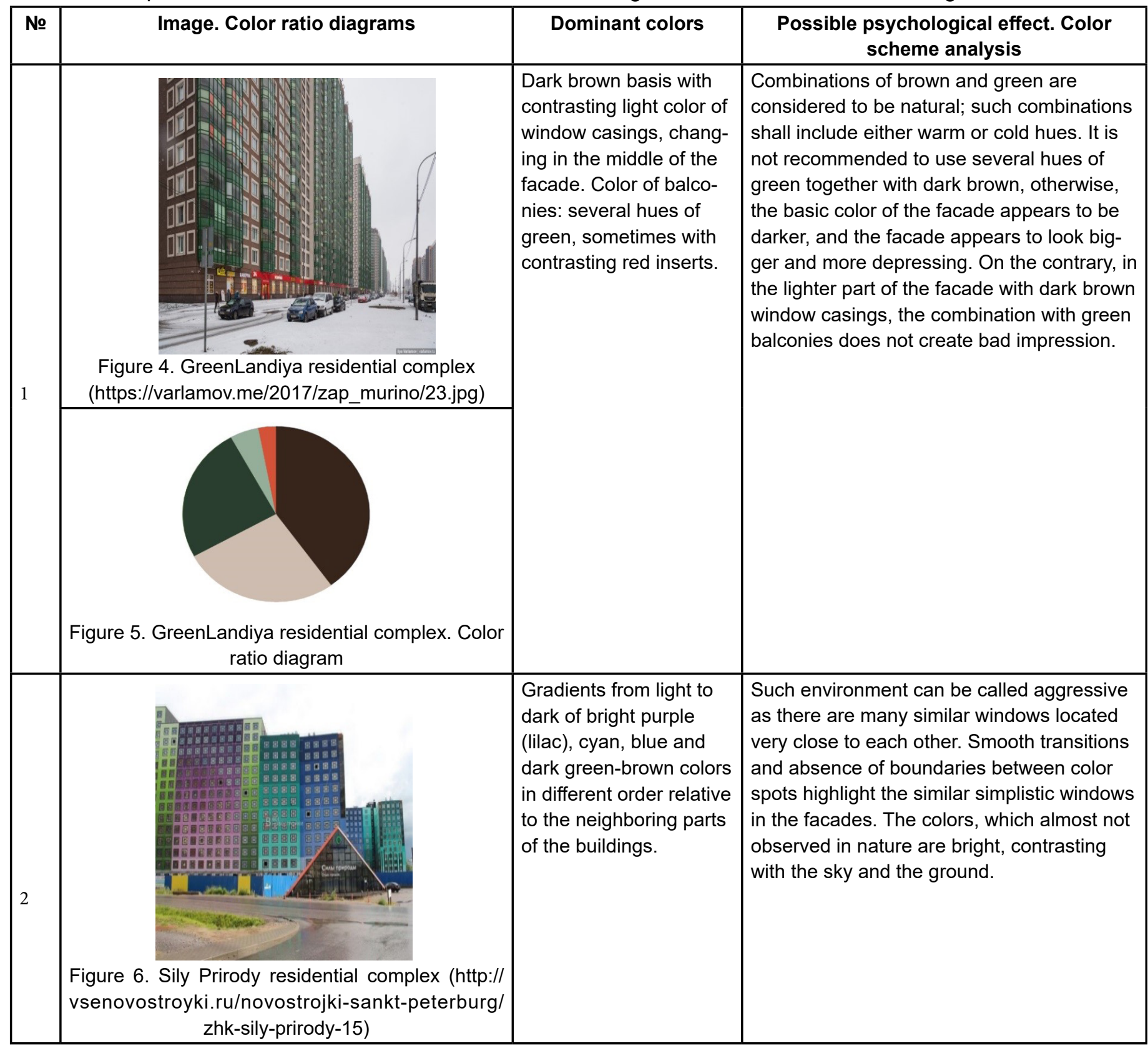




\begin{tabular}{|c|c|c|c|}
\hline & $\begin{array}{c}\text { Figure } 7 \text {. Sily Prirody residential complex. Color } \\
\text { ratio diagram }\end{array}$ & & \\
\hline \multirow[t]{2}{*}{3} & $\begin{array}{l}\text { Figure 8. Novoe Murino residential complex } \\
\text { (https://varlamov.me/2017/zap_murino/07.jpg) }\end{array}$ & $\begin{array}{l}\text { The dominant color } \\
\text { is dark brown with } \\
\text { orange-brown lines. } \\
\text { The balconies, glazing, } \\
\text { window casings, as well } \\
\text { as the semi-basement } \\
\text { are black. }\end{array}$ & $\begin{array}{l}\text { Pairs of color combination horizontal divi- } \\
\text { sions (black and brown, black and orange, } \\
\text { brown and orange) elongate the building } \\
\text { facade, which, in case of multi-story build- } \\
\text { ings, contributes to facade perception as } \\
\text { continuous walls. Instead of accent highlight- } \\
\text { ing, contrasting black and dark brown in the } \\
\text { semi-basement part represent strength and } \\
\text { inapproachability, separating the building } \\
\text { with a clear boundary from the environment. }\end{array}$ \\
\hline & $\begin{array}{l}\text { Figure 9. Novoe Murino residential complex. Color } \\
\text { ratio diagram }\end{array}$ & & \\
\hline 4 & $\begin{array}{l}\text { Figure 10. Dominanta residential complex (http:// } \\
\text { aktiv-spb.ru/services/uslugi-v-sfere-nedvizhimosti/ } \\
\text { arenda-nedvizhimosti/torgovye-pomeshcheniia/ar- } \\
\text { enda-pomeshchenii-tk-kosmos) }\end{array}$ & $\begin{array}{l}\text { The dominant color is } \\
\text { white with blue inserts. } \\
\text { Mirror glazing of several } \\
\text { hues of blue. }\end{array}$ & $\begin{array}{l}\text { The environment is homogeneous due to } \\
\text { the large amount of window glazing without } \\
\text { much details. The combination of white and } \\
\text { blue is considered to be visually pleasing } \\
\text { and should be soothing, however, bath- } \\
\text { rooms in residential and public buildings } \\
\text { usually have tiling of such blue color, and } \\
\text { subconscious comparison of those hues } \\
\text { results in the projection of the emotional } \\
\text { attitude and generalization of the images. } \\
\text { The mirror glazing causes discomfort: during } \\
\text { the day, it reflects the interior imposed upon } \\
\text { the reflection of the street or neighboring } \\
\text { buildings (Lam, 1977) }\end{array}$ \\
\hline
\end{tabular}




\section{Architecture and Engineering Volume 3 Issue 2}

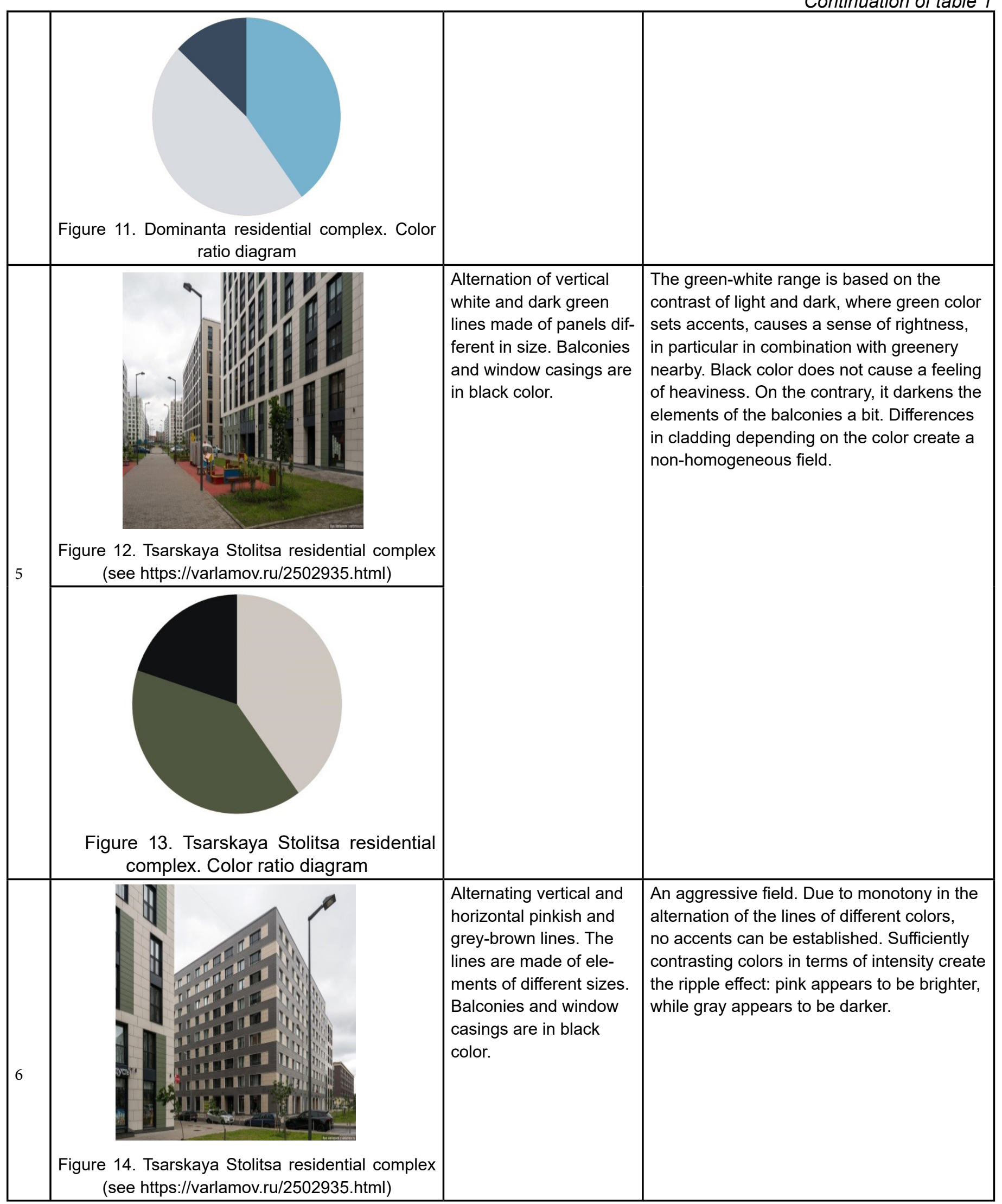




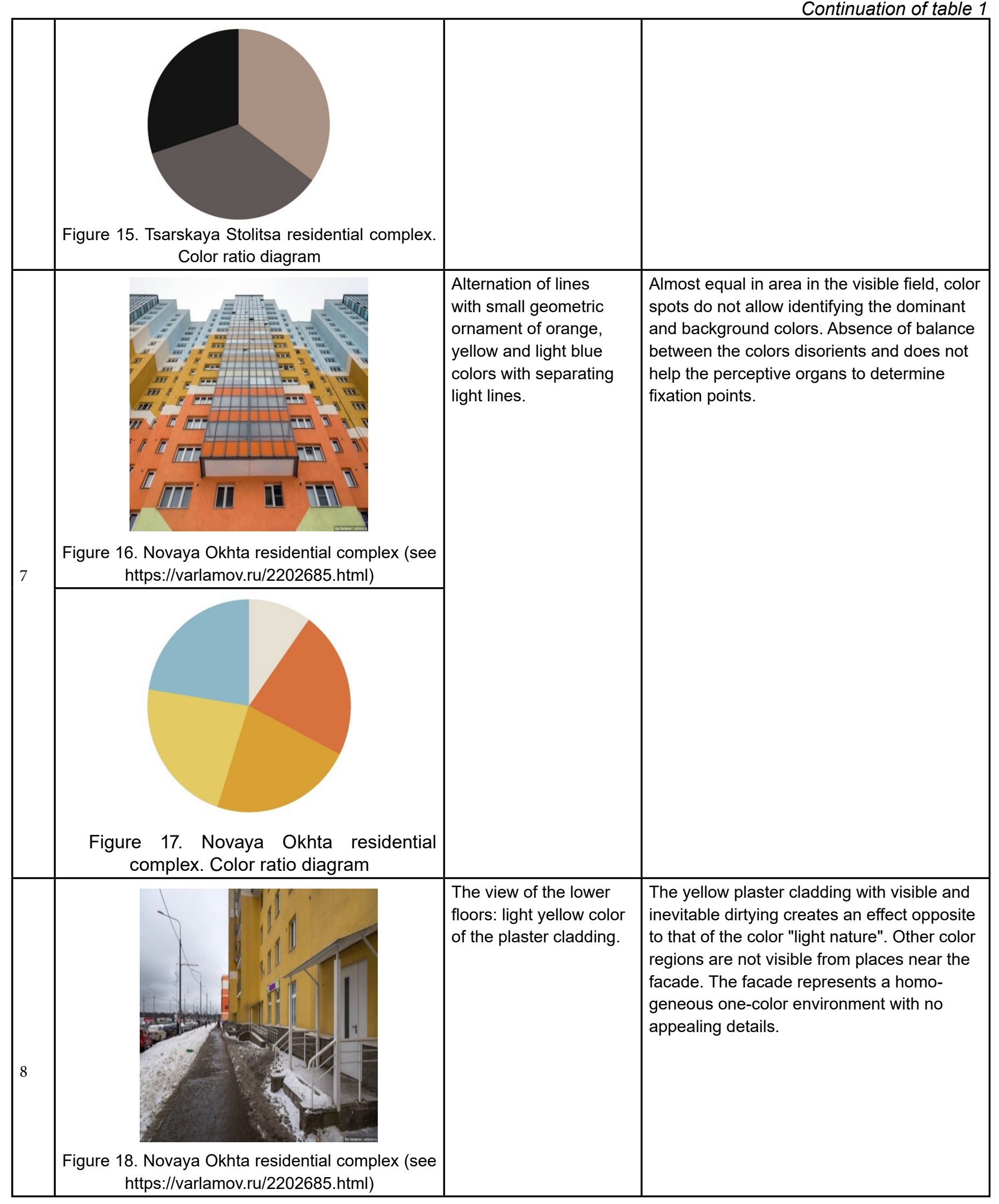




\section{Architecture and Engineering Volume 3 Issue 2}

Continuation of table 1

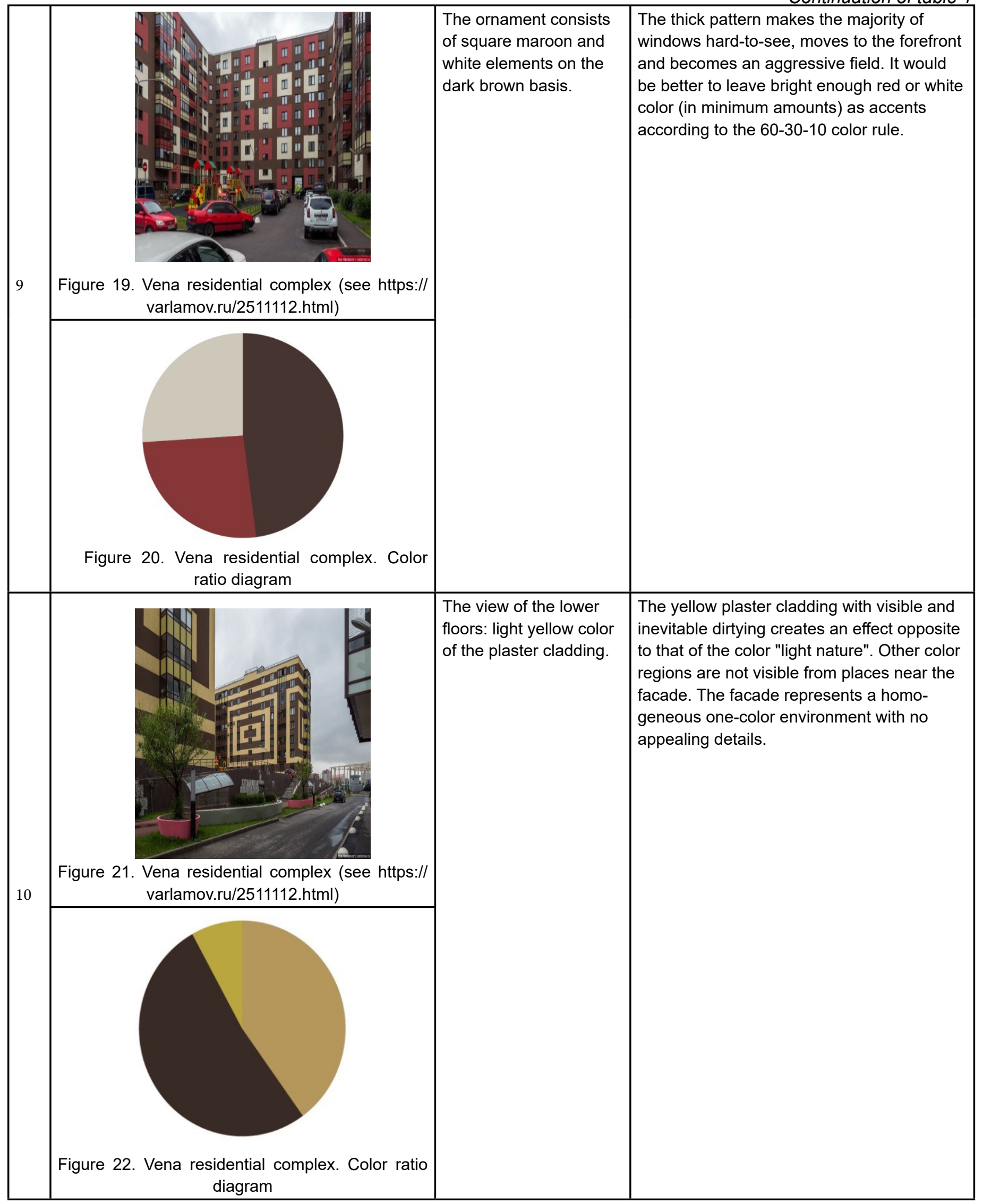




\section{Continuation of table 1}

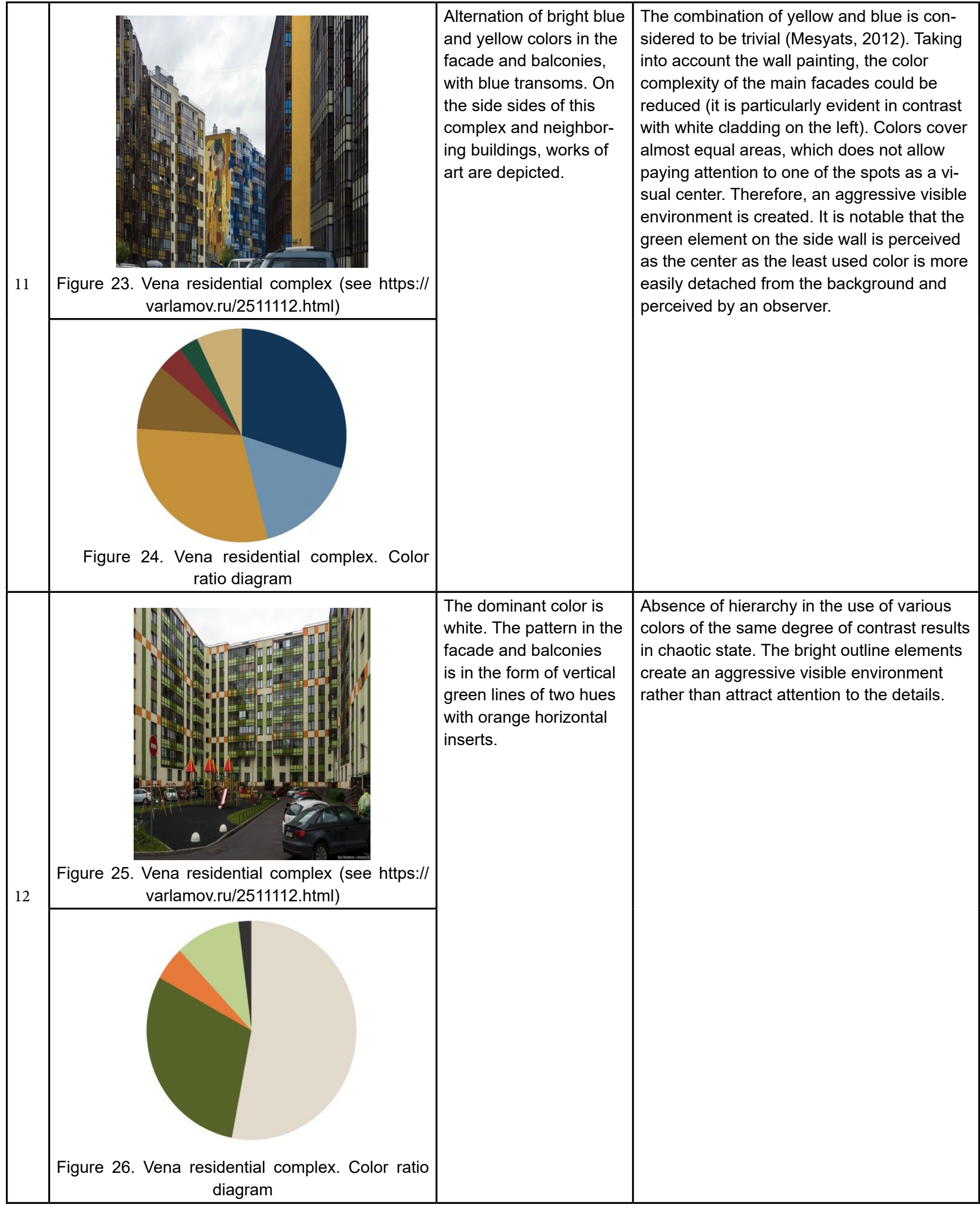




\section{Architecture and Engineering Volume 3 Issue 2}

Continuation of table 1

\begin{tabular}{|c|c|c|c|}
\hline \multirow[t]{2}{*}{13} & $\begin{array}{l}\text { 27. Vernisazh residential complex (see } \\
\text { https://spbhomes.ru/vernisazh) }\end{array}$ & $\begin{array}{l}\text { The dominant color of } \\
\text { the main facades is } \\
\text { white; the side walls } \\
\text { and semi-basement are } \\
\text { black. The geometric } \\
\text { pattern has several } \\
\text { hues of red and brown } \\
\text { colors. }\end{array}$ & $\begin{array}{l}\text { Chaotic disposition of color spots against } \\
\text { the white background is visually pleasing } \\
\text { and reduces the likelihood of aggressive } \\
\text { environment occurrence. The white and gray } \\
\text { glazing against the light and bright back- } \\
\text { ground is inconspicuous. The colorful details } \\
\text { against the black background include those } \\
\text { surfaces into the main facade. No effect of } \\
\text { individual continuous walls is created. }\end{array}$ \\
\hline & Figure 28. Vernisazh residential complex. & & \\
\hline 14 & $\begin{array}{l}\text { Figure 29. London residential complex (see http:// } \\
\text { Oklandia.ru/zhk_london_zhk_7_stolic) }\end{array}$ & $\begin{array}{l}\text { The dominant color is } \\
\text { dark brown. Alternation } \\
\text { of red, white, yellow and } \\
\text { gray-blue bay windows } \\
\text { with red inserts. }\end{array}$ & $\begin{array}{l}\text { When using dark brown color highlighting } \\
\text { lighter sections, a relation background/back- } \\
\text { ground instead of the relation background/ } \\
\text { accent appears due to the large area occu- } \\
\text { pied by the projecting parts representing an } \\
\text { aggressive environment. }\end{array}$ \\
\hline & Figure 30. London residential complex. Color ratio & & \\
\hline
\end{tabular}




\begin{tabular}{|c|c|c|c|}
\hline 15 & Figure 31. Severnaya Dolina residential complex & $\begin{array}{l}\text { The dominant color is } \\
\text { brown with horizontal } \\
\text { dark brown lines. The } \\
\text { black vertical elements } \\
\text { with windows alternate } \\
\text { with the balcony ele- } \\
\text { ments. }\end{array}$ & $\begin{array}{l}\text { Dark contrasting vertical lines visually } \\
\text { reduce the length of the building, which } \\
\text { has a positive effect. However, this effect is } \\
\text { evident only in the light sections but com- } \\
\text { pletely disappears against the dark brown } \\
\text { background. }\end{array}$ \\
\hline
\end{tabular}

up short color schemes for the main elements - the main color, the color of the basement, the framing of windows and balconies in the presence and their comparison with the studies of architects and theorists formulated in the literature.

\section{Results and Discussion}

It should be noted that the number of stories in a building and its effect on the human psychological condition were not taken into account.

Despite the consequences of urban planning of the 20th century, when in 10-15 years high-rise residential blocks became problem areas that afterwards were demolished or neglected (Robin Hood Gardens, Holly Street Estate in London, Cabrini-Green Homes in Chicago, Ballymun Flats in Dublin, Toulouse-le-Mirail in Toulouse), currently, one-off building construction projects are uncommon or do no occur at all. According to Table 1, a trend to use dark hues of brown and black can be traced. Those colors shall be used rarely and only to create accents (so that not to construct a building which would have a negative effect on the human psychological condition in the absence of sunlight). When using large areas with bright colors, the combination of schemes is not always selected correctly, and the cladding material does not always match the selected color or the combination. In most cases, facades have many windows or large glazed surfaces, including mirror glazing.

The following recommendations can be made:
1. When designing high-rise brick blocks, it is recommended to use light brown bricks with white brick joints. Thus, each element will appear to be smaller, lighter in color and weight, and the whole composition will look less depressing.

2. When constructing high-rise residential buildings, it is not recommended to make them long. In such case, the light coming between the buildings can highlight visual characteristics of the facade (Figure 33).

3. When using white color as the basis in several buildings, one contrasting insert is enough (Figures 33, 35). Contrasting lines of different buildings shall match (Figure 34) in terms of intensity and cold/warm color palette: light hues of warm gray, pink, red and aquamarine are used.

4. In Figure 36, despite the great length of the building, concrete elements change geometrically. The building also has color inserts with geometric patterns on four sides of embeddings which mutually complement the facade material.

5. An aggressive field can be reduced by increasing the area of glazing and alternating rows of clearances of various shapes with windows and balconies embedded in the facade (Figure 37).

6. If each building has only one color, then it is recommended to paint the neighboring buildings with more or less intense hue of the dominant color. The color of the neighboring building can be used to set accents around windows or the entrance space (Figure 38). 


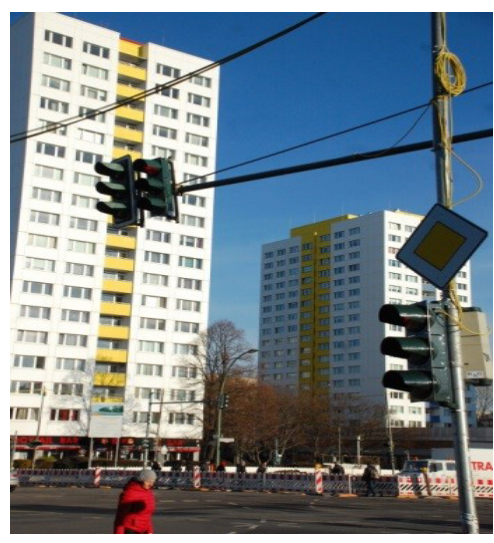

Figure 33. Berlin, Germany

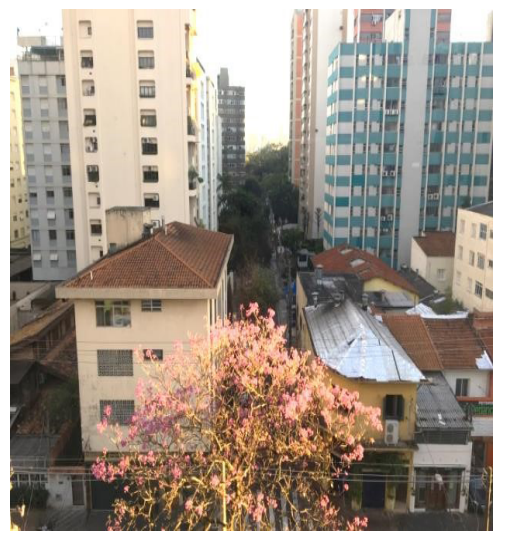

Figure 34. São Paulo, Brazil

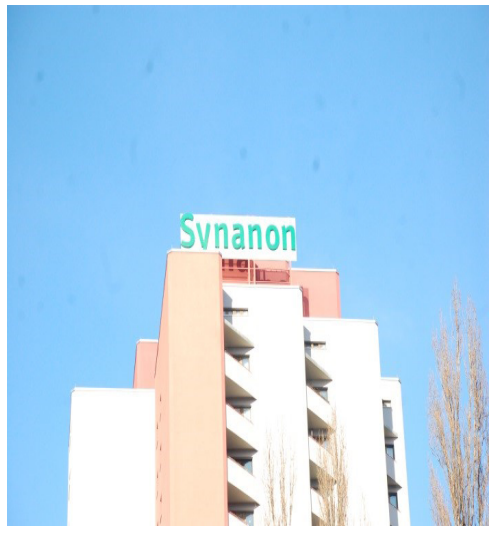

Figure 35. Berlin, Germany

\section{Conclusions}

The visual environment can vary even within one residential neighborhood. Due to this, it is necessary to coordinate the appearance of each residential complex with the neighboring ones, especially if they are built by different developers. In this case, the obvious difference in visually pleasing quality of the architectural space,

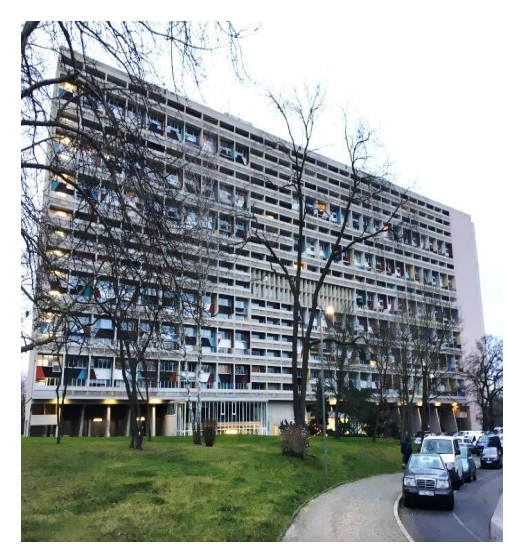

Figure 36. Unite d'Habitation. Berlin, Germany

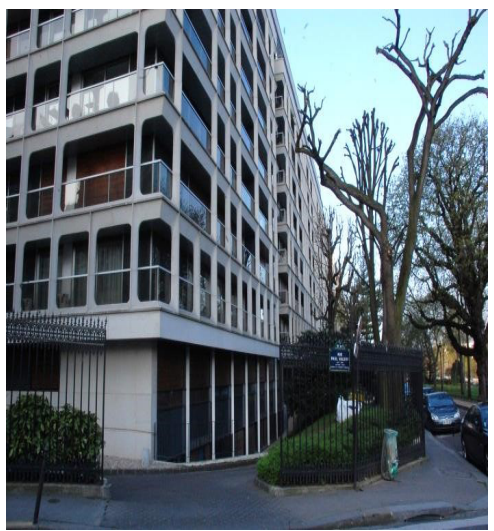

Figure 37. Paris, France

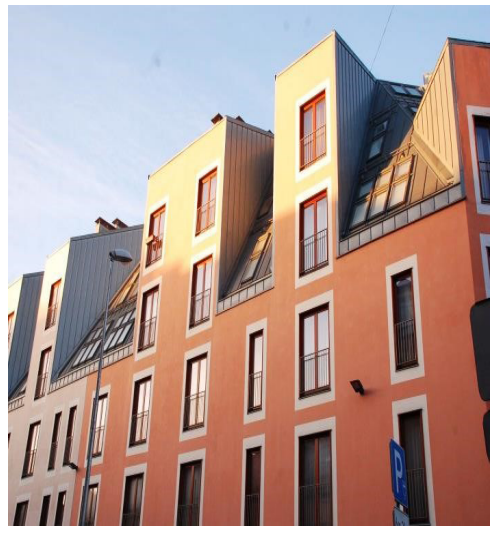

Figure 38. Riga, Latvia

where residents spend a lot of time and that, being on the outskirts of Saint Petersburg, represents the city identity for those driving by, can be reduced. Use of balanced color schemes, similar finish materials and details makes it possible to create residential neighborhoods having a unique single style and looking like a completed architectural ensemble. 


\section{References}

Asgarzadeh, M. (2012). Measuring oppressiveness of streetscapes. Landscape and Urban Planning, 107(1), pp. 1-11. DOI: 10.1016/j.landurbplan.2012.04.001

Azma, S., Katanchi, R. (2017). The Effect of Landscaping and Building Facades on Perceptual-Behavioral Features of Citizens. Journal of History Culture and Art Research, 6(3), pp. 264-281. DOI: 10.7596/taksad.v6i3.890

Banham, R., Barker, P., Hall, P., Price, C. (1969). Non-plan: an experiment in freedom. New Society, 338, pp. 435-443.

Birren, F. (1945). Selling with color. New York: McGraw-Hill Book Company, Inc.

Chechelnitsky, S. (2012). Videoehkologiya arkhitekturnoj sredy [Videoecology of the architectural environment]. Kharkiv: Kharkiv National Academy of Municipal Economy (in Russian).

Efimov, A. (1990). Koloristika goroda [City coloristics]. Moscow: Stroyizdat. (in Russian)

Feizi, M., Asadpour, A. (2013). The perception of citizens from the perspective of urban high-rise buildings: A case study of Shiraz Chamran Hotel. Journal of Iranian Architecture Studies, 2(3), pp. 107-121.

Filin, V. (1990). Vidimaya sreda v gorodskikh usloviyakh kak ehkologicheskij faktor [Visible environment in urban settings as an environmental factor]. Moscow: Nauka. (in Russian)

Frieling, H., Auer, X. (1973). Chelovek - Tsvet - Prostranstvo [Personality-Color-Space]. Moscow: Stroyizdat. (in Russian)

Gehl, J., Lotte, J., Reigstad, S. (2006). Close encounters with buildings. Urban Design International, 11, pp. 29-47. DOI: 10.1057/ palgrave.udi.9000162

Itten, J. (2013). Iskusstvo tsveta [The Art of Color]. Moscow: Publisher Dmitry Aronov. (in Russian)

Lam, W. (1977). Perception and lighting as formgivers for architecture. New York: McGraw-Hill Book Company, Inc.

Medd, D. (1949). Colour in Building. The Builder, 176, pp. 251-252.

Mesyats, S. (2012). logann Vol'fgang Gete i ego uchenie o tsvete [Johann Wolfgang von Goethe and His Color Theory (Part One)]. Moscow: Krug. (in Russian)

Poling, C. (1975). Bauhaus Color: an exhibition organized by the High Museum of Art. Atlanta: The High Museum of Art.

Pugh, E. (2014). Architecture, politics, and identity in divided Berlin (Culture, Politics, and the Built Environment). Pittsburgh: University of Pittsburgh Press.

Rahmatabadi, S. (2011). Psychology of colors and architectural facade and interior color selection. Australian Journal of Basic and Applied Sciences, 5 (12), pp. 215-219.

Ruskin, J. (2017). Sem' svetochej arkhitektury [The Seven Lamps of Architecture]. Saint Petersburg: Palmira. (in Russian)

Utaberta, N., Jalali, A., Johar, S., Surat, M., Che-Ani, A. (2012). Building Facade Study in Lahijan City, Iran: The Impact of Facade's Visual Elements on Historical Image. International Journal of Humanities and Social Sciences, 6 (7), pp. 1839-1844.

Yoshizawa, Y., Hibino, H., Koyama, S. (2007). Color Selection of Architectural Facade Taking into Consideration Surrounding Environment in Japan. Available at: https://www.sd.polyu.edu.hk/iasdr/proceeding/papers/Color\%20Selection\%20of\%20 Architectural\%20Facade\%20Taking\%20into\%20Consideration\%20Surrounding.pdf (accessed on 18.11.2017)

Zabelshansky, G. (1985). Arkhitektura i ehmotsional'nyj mir cheloveka [Architecture and emotional world of humans]. Moscow: Stroyizdat. (in Russian) 